\title{
Endoscopic cubital tunnel decompression: state of the art
}

\author{
Margaret W Fok, ${ }^{1}$ Tyson Cobb, ${ }^{2}$ Gregory lan Bain $\circledast^{3}$
}

${ }^{1}$ Department of Orthopaedics and Traumatology, Queen Mary Hospital, Hong Kong, Hong Kong

${ }^{2}$ Shoulder, Elbow, Wrist and Hand Center of Excellence, Clinton, Indiana, USA ${ }^{3}$ Department of Orthopaedic Surgery, Flinders University, North Adelaide, South Australia, Australia

Correspondence to Dr Margaret W Fok, Department of Orthopaedics and Traumatology, Queen Mary Hospital, Hong Kong, Hong Kong;

margaret_fok@yahoo.com

Received 7 August 2020 Revised 17 November 2020 Accepted 24 November 2020 Published Online First 28 January 2021

Check for updates

(C) International Society of Arthroscopy, Knee Surgery and Orthopaedic Sports Medicine 2021. No commercial re-use. See rights and permissions. Published by BMJ.

To cite: Fok MW,

Cobb T, Bain GI. J ISAKOS

2021:6:367-374.

\section{ABSTRACT}

Cubital tunnel syndrome is a common compressive neuropathy of the upper limb. Surgical decompression is indicated for patients who failed conservative therapy. Decompression in situ has shown to achieve comparable outcomes as decompression with anterior transposition in idiopathic cubital tunnel syndrome. Endoscopic cubital tunnel decompression has gained popularity in recent years, as surgeons can attain decompression of the ulnar nerve along its course using a small incision. Results from randomised controlled studies and systematic reviews, comparing endoscopic with open decompression in situ, are promising. Cases in which anterior transposition of the ulnar nerve is needed, an endoscopic technique can still be used by creating an additional volar portal, for the mobilisation of ulnar nerve. Early short-term results are encouraging. Further adequately powered, prospective, preferably double-blinded, randomised study are needed.

\section{INTRODUCTION}

Cubital tunnel syndrome is the second most common compressive neuropathy, following carpal tunnel syndrome. It involves compression and traction of the ulnar nerve along its path across the elbow. Its initial presentation varies, from episodic numbness of the ring finger and little finger of the affected limb, to a decrease in grip strength of the affected hand, to a claw hand deformity of the ulnar 2 fingers and intrinsic hand muscle wasting.

In the early phase of the cubital tunnel syndrome with patients predominantly suffering from subjective sensory symptoms and mild grip and pinch weakness without muscle atrophy (ie, Dellon type 1 and $2^{1}$ and McGowan type 1 and $2 \mathrm{~A}^{23}$ ) (table 1 ), conservative therapy including activity modification, physiotherapy and splinting is the treatment of choice. Yet, in cases of the presence of sensory or motor deficit or of persistent symptoms despite a period of conservative therapy, surgical decompression is recommended. ${ }^{4}$

Open decompression of the ulnar nerve with or without transposition is the conventional treatment of choice for cubital tunnel syndrome. ${ }^{1}$ Recently, the use of endoscopic instruments in the aid of ulnar nerve decompression has gain popularity. ${ }^{5}$ This state-of-the-art article is to present indications in performing endoscopic cubital tunnel decompression, with and without anterior transposition, its techniques and its outcomes.

\section{ANATOMY AND ITS SURGICAL RELEVANCE}

Anatomically, there are numerous common potential sites of ulnar nerve compression at the elbow (figure 1). ${ }^{6}$ Proximally, Arcade of Struthers is a deep band of brachial fasciae between the medial triceps and the intermuscular septum, which lies about $8-10 \mathrm{~cm}$ proximal to the medial epicondyle. ${ }^{7}$ As the ulnar nerve enters the cubital tunnel, posterior to the medial epicondyle, the thickened Osbourne ligament (also known as cubital tunnel retinaculum) which originates from the medial epicondyle and humeral head of the flexor carpi ulnaris (FCU) and inserts onto the olecranon and the ulnar head of the FCU, can narrow the cubital tunnel and lead to ulnar nerve compression. In addition, osteophytes arising from the medial epicondyle, in the presence of elbow osteoarthritis, may result in external compression of ulnar nerve. In some patients, an anomalous anconeus epitrochlearis muscle can also be a source of ulnar nerve compression. ${ }^{7}$ As the ulnar nerve exits the cubital tunnel and courses distally into the FCU muscle, the thickened aponeurosis of the two head of FCU muscle is a potential site of compression.

Ulnar nerve transverses from the anterior compartment of the brachium to the posterior compartment and lies posterior to the medial intermuscular septum (MIMS) before entering the cubital tunnel. While MIMS is not an usual site of ulnar nerve compression in idiopathic cubital tunnel syndrome, MIMS may compress onto the ulnar nerve at its new course in anterior transposition. As a result, it is recommended to excise MIMS during ulnar nerve transposition. ${ }^{8}$

\section{ULNAR NERVE DECOMPRESSION AND TRANSPOSITION}

Surgical intervention for cubital tunnel syndrome was first described in late 1890 s by Curtis. ${ }^{1}$ Since then, numerous methods of ulnar nerve decompression have been described, including simple decompression, medial epicondylectomy, decompression with subcutaneous transposition, decompression with intramuscular transposition and decompression with submuscular transposition. While there was no consensus on the most preferred surgical method on managing cubital tunnel syndrome, it was believed that decompression with anterior transposition could place the nerve back into a 'normal intermuscular interval adjacent to the median nerve," and result in the best outcome especially in the group with moderate severity (Dellon II and McGowan II). ${ }^{1}$

\section{ENDOSCOPIC CUBITAL TUNNEL DECOMPRESSION}

In the 2000s, four prospective, randomised clinical trials ${ }^{10-13}$ comparing decompression in situ and anterior transposition were published. 


\begin{tabular}{lll}
\hline Table 1 & Dellon and McGowan classification & McGowan classification \\
\hline Grade & Dellon classification & $\begin{array}{l}\text { Subjective sensory symptoms without objective loss of two-point sensibility } \\
\text { Subjective weakness, clumsiness or loss of coordination without muscle atrophy }\end{array}$ \\
\hline Type 1: mild & $\begin{array}{l}\text { Subjective sensory symptoms without objective loss of two-point sensibility } \\
\text { Objective weakness in pinch/grip strength without muscle atrophy }\end{array}$ & A: Intrinsic strength with a muscle grade of 4 out of 5 without muscle atrophy \\
& $\begin{array}{l}\text { Abnormal two-point discrimination (static } \geq 6 \mathrm{~mm}, \text { moving } \geq 4 \mathrm{~mm} \text { ) } \\
\text { Objective weakness in pinch/grip strength with significant muscle atrophy }\end{array}$ & B: Intrinsic strength with a muscle grade of 3 out of 5 with incomplete intrinsic atrophy \\
\hline
\end{tabular}

Decompression in situ was able to achieve comparable outcomes as subcutaneous anterior transposition, ${ }^{12}$ and submuscular transposition $^{11} 13$ in both short-term and long-term (at least 3 years) follow-up. ${ }^{10}$ Complication rates were noted to be significantly higher with anterior transposition as compared with decompression in situ. ${ }^{11} 12$ A recent Cochrane review drew similar conclusions. ${ }^{14}$ Since then, trend in surgical treatment of cubital tunnel syndrome has shifted to decompression in situ. ${ }^{15} 16$

Endoscopic cubital tunnel decompression was first described by Tsai et al in $1995 .{ }^{17}$ Under endoscopic guidance, ulnar nerve can be released from the Arcade of Struthers proximally to the heads of FCU muscles distally. With early results showing satisfactory outcomes, minimal complications and small incision (ie, smaller than open decompression in situ ${ }^{18-25}$ ), endoscopic cubital tunnel has gained popularity in recent years. ${ }^{5}$ Different instruments dedicated for cubital tunnel release have been introduced into the market. It can be classified into two types: the use of task-specific equipment: Storz instruments (Karl Storz, Tuttlingen, Germany) 2126 and Agee device (3M, Orthopedic Products, St Paul, Minnesota, USA $)^{20} 27$ and the use of cannula (Integra LifeSciences, Plainsboro, New Jersey, USA) ${ }^{28} 29$ (Ace Glass, Louisville, Kentucky, USA). ${ }^{17}$ Each surgical technique including its tips and tricks will be discussed.

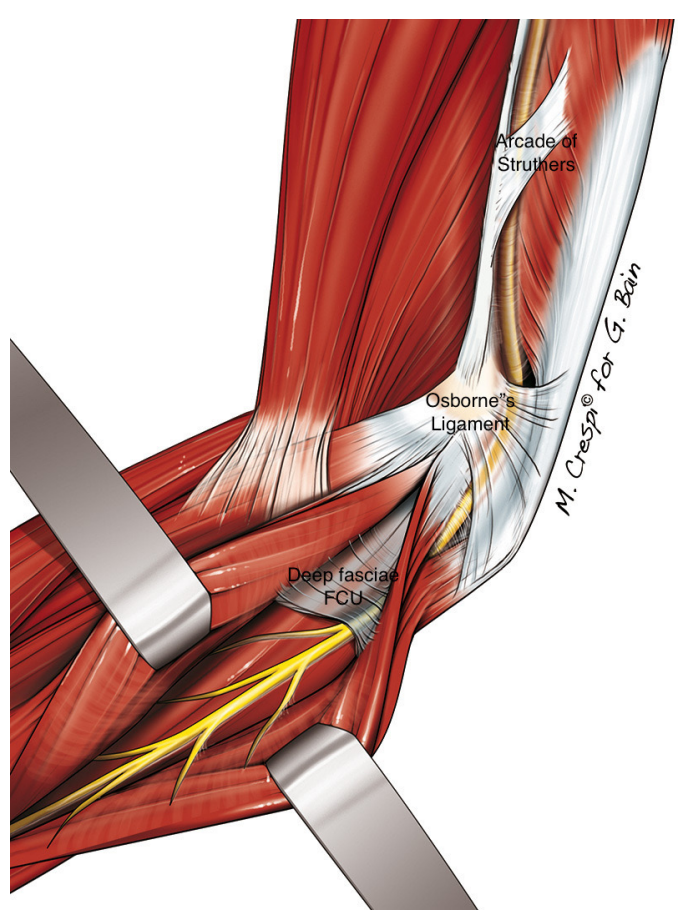

Figure 1 Sites of ulnar nerve compression around the elbow (copyright Professor Greg Bain and Mr Max Crespi). FCU, flexor carpi ulnaris.

\section{Indications}

- Idiopathic cubital tunnel syndrome

- Nerve conduction study is preferable for diagnosis, baseline measurements and prognostic indications.

\section{Contraindications}

- Lesion or mass that could be compressing onto the ulnar nerve

- Hostile bed of the ulnar nerve, for example, excessive scarring from previous trauma.

- Severe elbow contracture.

- Concomitant conditions requiring the ulnar nerve to be transposed, for example, corrective surgery for humeral or elbow malalignment

- Recurrent cubital tunnel syndrome.

- Ulnar nerve hypermobility, that is, subluxation or dislocation of ulnar nerve during elbow movement. This is a relative contraindications for some surgeons. (Refer to section on hypermobility of ulnar nerve)

- Limited external rotation of the shoulder.

- Relative contraindication-lack of surgeons' expertise.

\section{SURGICAL PROCEDURE FOR ENDOSCOPIC ULNAR NERVE DECOMPRESSION}

Following an anaesthetic, with the patient in supine position, tourniquet and arm table, the ulnar nerve is palpated posterior to the medial epicondyle. A $2 \mathrm{~cm}$ longitudinal skin incision is made over the retrocondylar groove, between the medial condyle and the olecranon (figure 2). The ulnar nerve is then identified by incising the roof of the cubital tunnel.

For surgical technique using Storz Equipment (Karl Storz) ${ }^{2630}$ : we use the tunnelling forceps to create a space between the subcutaneous tissue and fasciae, starting from the medial epicondyle, to $10-12 \mathrm{~cm}$ proximally and $8-10 \mathrm{~cm}$ distally. An illuminated

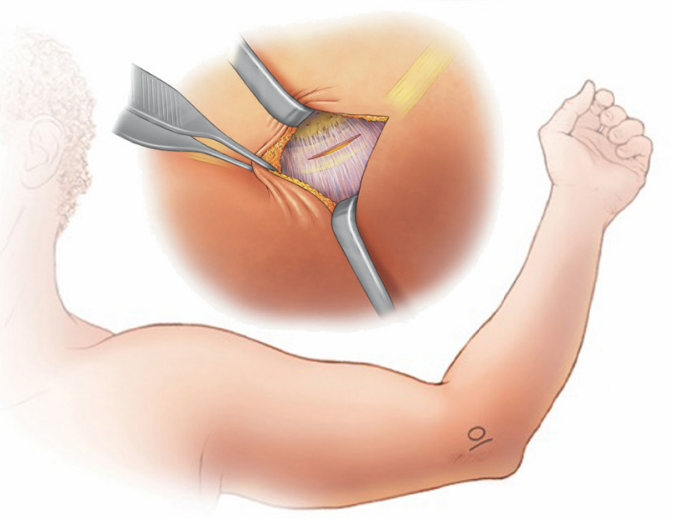

Figure 2 Incision over the retrocondylar groove. Inlet: identification of ulnar nerve (copyright Professor Greg Bain and Mr Max Crespi). 


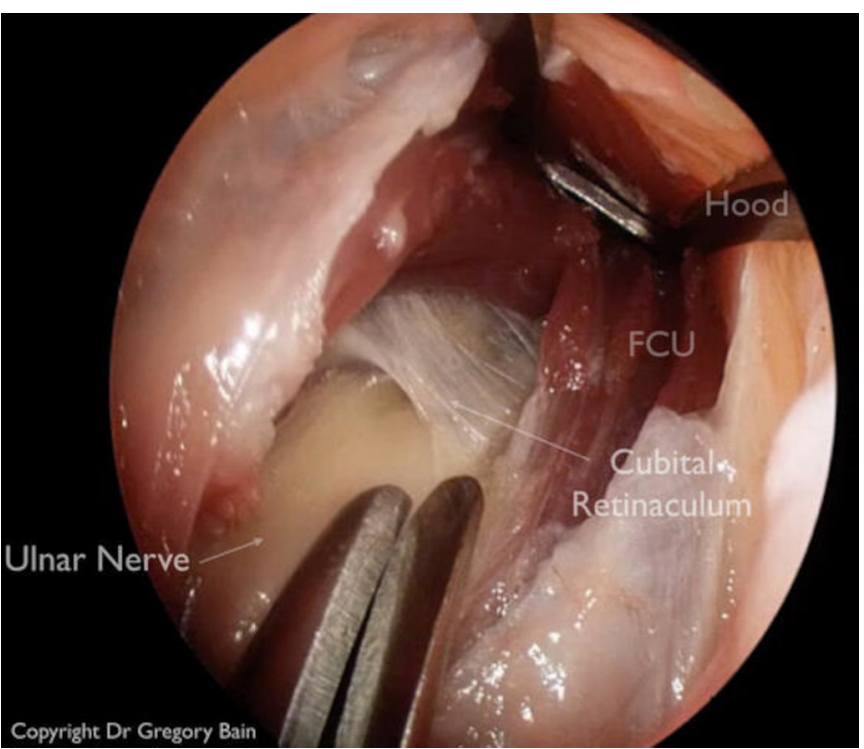

Figure 3 Endoscopic view of distal release using endoscope and taskspecific equipment. Inlet: instrument used (copyright Professor Greg Bain and Mr Max Crespi). FCU, flexor carpi ulnaris.

speculum is then inserted into this prepared space. Under direct vision, the roof of the cubital tunnel is divided.

A $4 \mathrm{~mm} 30^{\circ}$ endoscope with a blunt dissector on its tip is introduced into the incision. The dissector is used to lift up the soft tissue, enabling better visualisation of the ulnar nerve and its surrounding tissue. Under endoscopic guidance, the forearm fasciae and the fibrous raphe between the two muscular heads of the FCU over the ulnar nerve are being cut by a blunted tipped scissors (figure 3). We release the ulnar nerve from all of its overlying soft tissue until the motor branches of the FCU come into view. This is around $8 \mathrm{~cm}$ distal to the medial epicondyle.

The endoscope is used to decompress the proximal ulnar nerve similarly. The deep fasciae and the Arcade of Struthers above the ulnar nerve are divided, up to $10 \mathrm{~cm}$ proximal to the medial epicondyle. No excision of MIMS is needed, if there is

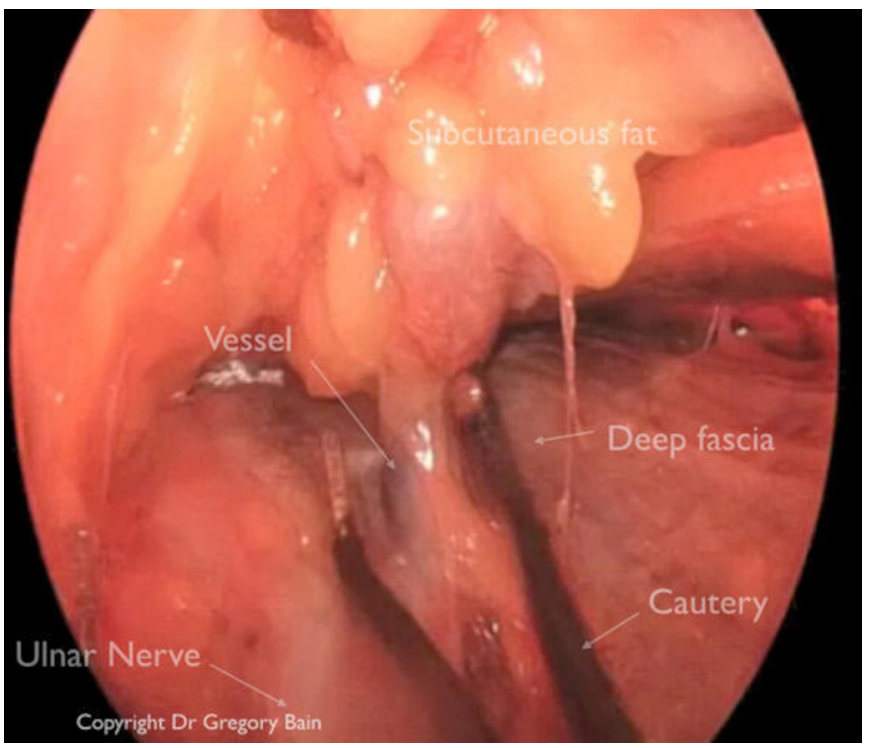

Figure 4 Endoscopic view of haemostasis by using bipolar cautery (copyright Professor Greg Bain and Mr Max Crespi).

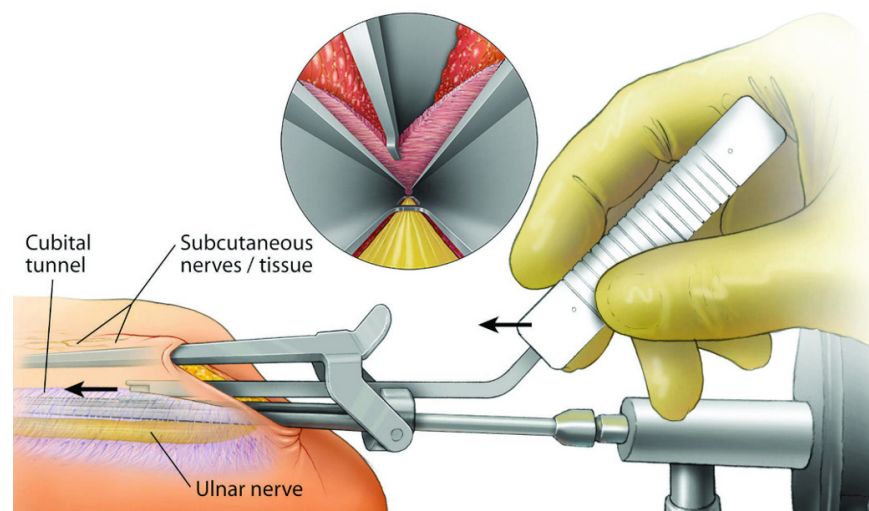

Figure 5 Illustration of endoscope and cannula in place. Inlet: endoscopic view (copyright Dr Tyson Cobb).

no obvious impingement over the course of the ulnar nerve. Haemostasis is achieved with long bipolar cautery (figure 4).

For surgical technique using Cannula (Integra Life Sciences, Plainsboro, New Jersey, USA) ${ }^{29} 31$ : after incising the roof of the cubital tunnel and the identification of the ulnar nerve, a spatula is inserted into the space between the ulnar nerve and roof of the tunnel. A canal is created both proximally and distally by advancing the spatula into the space without resistance.

\begin{tabular}{|c|c|}
\hline Bishop rating system & Points \\
\hline \multicolumn{2}{|l|}{ Satisfaction } \\
\hline Satisfied & 2 \\
\hline Satisfied with reservation & 1 \\
\hline Dissatisfied & 0 \\
\hline \multicolumn{2}{|l|}{ Improvement } \\
\hline Better & 2 \\
\hline Unchanged & 1 \\
\hline Worse & 0 \\
\hline \multicolumn{2}{|l|}{$\begin{array}{l}\text { Severity of residual symptoms } \\
\text { (pain, paraesthesia, dysethesia, weakness, clumsiness) }\end{array}$} \\
\hline Asymptomatic & 3 \\
\hline Mild-occasional & 2 \\
\hline Moderate & 1 \\
\hline Severe & 0 \\
\hline \multicolumn{2}{|l|}{ Work status } \\
\hline Working or able to work at previous job & 1 \\
\hline Not working secondary because of ulnar neuropathy & 0 \\
\hline \multicolumn{2}{|l|}{ Leisure activity } \\
\hline Unlimited & 1 \\
\hline Limited & 0 \\
\hline \multicolumn{2}{|l|}{ Strength } \\
\hline Both grasp and pinch strength $80 \%$ or greater, compared with other hand & 2 \\
\hline Either grasp or pinch (but not both) <80\% & 1 \\
\hline Both grasp and pinch $<80 \%$ & 0 \\
\hline \multicolumn{2}{|l|}{ Sensibility (static two-point discrimination) } \\
\hline Normal $(\leq 5 \mathrm{~mm})$ & 1 \\
\hline Abnormal $(>5 \mathrm{~mm})$ & 0 \\
\hline Total & 12 \\
\hline Bishop rating & Bishop score \\
\hline Excellent & $10-12$ \\
\hline Good & $7-9$ \\
\hline Fair & $4-6$ \\
\hline Poor & $0-3$ \\
\hline
\end{tabular}




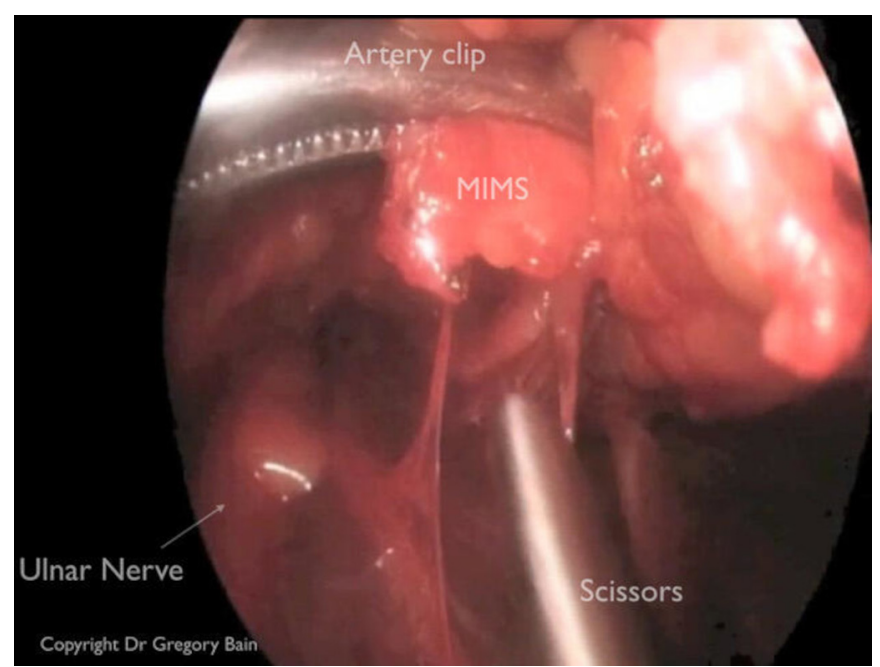

Figure 6 Excision of medial intermuscular septum (MIMS) while protecting the ulnar nerve (copyright Professor Greg Bain and Mr Max Crespi).

A cannula specifically designed for cubital tunnel decompression is used. It has a flat undersurface, in order to hold the ulnar nerve under the cannula, and slots on the inferior surface, in order to allow visualisation of the nerve during decompression. The cannula has an attached retractor, which holds the soft tissue and the cutaneous nerve, above the fasciae. The cannula with trocar is introduced into the canal and is first advanced proximally between the roof of the canal and the ulnar nerve. The attached retractor slides above the fasciae, retracting the soft tissue and cutaneous nerves. When resistance is encountered, the cannula is withdrawn. A spatula is then reinserted to clear the canal, between the nerve and the undersurface of the

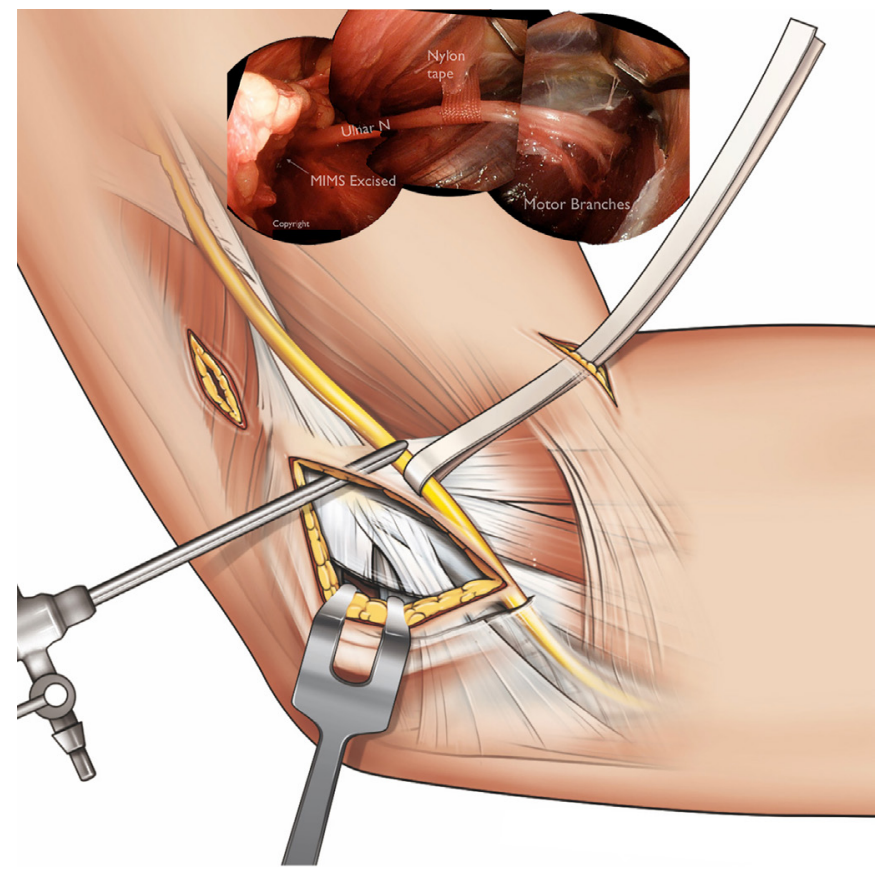

Figure 7 Additional portal for anterior transposition for ulnar nerve mobilisation. An additional proximal incision can also be made to retract the nerve from the medial intermuscular septum (MIMS) prior to its excision. Inlet: ulnar nerve was mobilised with a nylon tape (copyright Professor Greg Bain and Mr Max Crespi).

\section{Box 1 Key articles}

1. Lee Dellon A. Review of treatment results for ulnar nerve entrapment at the elbow. J Hand Surg Am. 1989 Jul; 14(4), 688-700.

2. Staples, J. R., \& Calfee, R. (2017). Cubital tunnel syndrome: current concepts. The Journal of the American Academy of Orthopaedic Surgeons, 25(10), e215-e224.

3. Bain, G. I., \& Bajhau, A. (2005). Endoscopic release of the ulnar nerve at the elbow using the agee device: a cadaveric study. Arthroscopy: the Journal of Arthroscopic \& Related Surgery: Official Publication of the Arthroscopy Association of North America and the International Arthroscopy Association, 21(6), 691-695.

4. Hoffmann, R., \& Lubahn, J. (2013). Endoscopic cubital tunnel release using the Hoffmann technique. The Journal of Hand Surgery, 38(6), 1234-1239.

5. Cobb, T. K. (2010). Endoscopic cubital tunnel release. The Journal of Hand Surgery, 35(10), 1690-1697.

6. Dützmann, S., Martin, K. D., Sobottka, S., Marquardt, G., Schackert, G., Seifert, V., \& Krishnan, K. G. (2013). Open vs retractor-endoscopic in situ decompression of the ulnar nerve in cubital tunnel syndrome: a retrospective cohort study. Neurosurgery, 72(4), 605-16-discussion 614-6.

7. Schmidt, S., Kleist Welch-Guerra, W., Matthes, M., Baldauf, J., Schminke, U., \& Schroeder, H. W. S. (2015). Endoscopic vs open decompression of the ulnar nerve in cubital tunnel syndrome: a prospective randomised double-blind study. Neurosurgery, 77(6), 960-70-discussion 970-1.

8. Buchanan, P. J., Chieng, L. O., Hubbard, Z. S., Law, T. Y., \& Chim, H. (2018). Endoscopic versus open in situ cubital tunnel release: a systematic review of the literature and meta-analysis of 655 patients. Plastic and Reconstructive Surgery, 141(3), 679-684.

9. Morse, L. P., McGuire, D. T., \& Bain, G. I. (2014). Endoscopic ulnar nerve release and transposition. Techniques in Hand \& Upper Extremity Surgery, 18(1), 10-14.

10. Martin, K. D., Dützmann, S., Sobottka, S. B., Rambow, S., Mellerowicz, H. A., Pinzer, T., et al. (2014). Retractorendoscopic nerve decompression in carpal and cubital tunnel syndromes: outcomes in a small series. World Neurosurgery, 82(1-2), e361-e370.

fasciae. We can also use the endoscope to ensure that the fasciae is cleared of soft tissue and cutaneous nerves.

Once the cannula and trocar is in place within the canal, the trocar is removed. A $4 \mathrm{~mm} 30^{\circ}$ endoscope is inserted into the cannula. The inferior slot of the cannula is viewed, confirmed that the ulnar nerve is protected by the cannula (figure 5). A blade is then insertred along the superior slot of the cannula to divide the fasciae. The completeness of the release can be confirmed by gradually pulling the cannula back on the scope and out of the canal.

A similar procedure is performed for the distal release.

\section{Box 2 Validated outcome measures and classifications}

Dellon classification.

- McGowan classification.

- Bishop score.

- Disabilities of the Arm, Shoulder and Hand score. 


\section{Box 3 Key issues of patient selection}

For endoscopic cubital tunnel decompression.

- Idiopathic cubital tunnel syndrome.

- Diagnosed by history and physical examination.

- Objective and subjective sensory and motor deficit should be documented.

- Status of provocative tests including Tinel signs and elbow flexion test.

- Stability of ulnar nerve.

- Nerve conduction study is recommended for the confirmation of cubital tunnel syndrome.

\section{Indication for endoscopic ulnar nerve anterior \\ transposition.}

- Hostile ulnar nerve bed, for example, excessive scarring from previous trauma.

- Symptomatic hypermobility of ulnar nerve.

- Cubitus valgus.

- Previous incomplete decompression of ulnar nerve.

\section{Contraindication for endoscopic procedure.}

- Previous trauma or surgery to the ulnar nerve and/or elbow.

- Severe elbow contracture.

- Concomitant pathology necessitating open surgery such as the corrective osteotomy for distal humeral malalignment.

- Patients' particular condition requiring submuscular transposition, for example, patients who are slim and are susceptible to ulnar nerve irritation.

- Lack of technical expertise.

For surgical technique using Agee device (Orthopedic Prod$u c t s)^{20}{ }^{32}$ : this uses the Agee device designed for endoscopic carpal tunnel release. It shares similar technical details as the cannula technique.

\section{Box 4 Essential and/or typical features of surgical} procedure.

- Identification of the ulnar nerve at the retrocondylar groove.

- Use of blunted instrument to develop space between soft tissue and deep fasciae of arm and forearm.

- Dissect the nerve from adjacent tissues and fibrous band prior to the incision of the deep fasciae.

- Adequate length of ulnar nerve decompression.

- Proximally: 8-10 cm from medial epicondyle (including Arcade of Struthers).

- Distally: up to $8 \mathrm{~cm}$ from medial epicondyle until the muscular branch(es) of flexor carpi ulnaris is encountered.

- Check for stability of ulnar nerve after decompression. - Prepare for anterior transposition if necessary.

- Achieve haemostasis prior to closure.

Ulnar nerve anterior transposition.

- Preservation of ulnar nerve, its branches and its accompanied vessels during mobilisation.

- Excision of medial intermuscular septum during anterior transposition.

- Ensure that a new nerve compression site is not created after transposition.

- Observe the nerve stability throughout total elbow motion.

\section{Box 5 Tips and tricks}

- Be comfortable with the surgical equipment. Consider a trial with cadaveric materials.

- For the initial few cases, use a larger incision to familiarise with the technique.

- For the initial few cases, it is advisable to perform endoscopic decompression in thin patients as their anatomy can be easily identified and the ulnar nerve more easily localised.

- A more generous incision is required for patients with obesity or overweight patients.

- Beware of cutaneous nerves which may be encountered in the incision and during the development of subcutaneous tunnel.

- The hooded scope must be advanced without resistance. Cases in which resistance is encountered, instruments should be withdrawn. The tunnel/canal should be checked. If in doubt, surgeons should extend the incision for better visualisation.

- Ulnar nerve must be well visualised during the dissection of soft tissue. Ulnar nerve must be well protected during the incision of the deep fasciae.

- For endoscopic decompression in situ, circumferential dissection of the ulnar nerve is not recommended. This is to minimise devascularisation of the ulnar nerve and to avoid its subluxation.

- During distal dissection, beware of the motor branches of flexor carpi ulnaris, branching out from the main trunk of the ulnar nerve.

- Good haemostasis is necessary to prevent postoperative haematoma. We recommend to deflate the tourniquet prior to wound closure. Infiltration with a local anaesthetic with epinephrine may be helpful. A drain may be inserted if in doubt.

- Ulnar nerve stability is observed throughout total elbow motion. If subluxation or dislocation of the nerve is noted, anterior transposition is indicated.

- If ulnar nerve cannot be well visualised or haemostasis cannot be achieved, surgeons should convert to an open procedure.

\section{For anterior transposition:}

- Surgeons should familiarise with endoscopic cubital tunnel decompression prior to his/her attempt in performing endoscopic anterior transposition.

- During the mobilisation of the ulnar nerve from its native bed, assistants must avoid pulling the ulnar nerve by a nylon tape with excessive force or traction. An inadvertent ulnar nerve injury may be resulted.

- Ulnar nerve and vessels should be mobilised together in order to prevent the devascularisation of the ulnar nerve.

- Excise MIMS in a generous manner. If the ulnar nerve is in close proximity to the medial intermuscular septum (MIMS), an additional proximal incision is made to retract the nerve from MIMS prior to its excision.

- Prior to closure, surgeons must ensure that there is no new compression site along the new course of the ulnar nerve. The ulnar nerve is stable in its new course.

Once ulnar nerve is identified, a spatula is used to dissect the nerve from the surrounding soft tissue and fasciae. Then, instead of inserting the cannula/trocar, the Agee endoscope is inserted 


\section{Box 6 Major pitfalls}

- Incorrect diagnosis.

- Incomplete decompression of the ulnar nerve.

- latrogenic injury to the medial antebrachial cutaneous nerve of the arm during incision and dissection.

- Inadvertent injury of the ulnar nerve or its branches during decompression.

- Haematoma formation by developing numerous planes during soft tissue dissection.

- Meticulous haemostasis using long bipolar cautery is needed prior to wound closure.

- Unrecognised subluxation/dislocation of the ulnar nerve.

Wound dehiscence.

\section{For anterior transposition:}

- Devascularisation of the ulnar nerve by dissecting its accompanied vessels from the nerve.

- Ulnar nerve subluxates back to its native course during elbow movement.

- The creation of new site of ulnar nerve compression in its new course.

into the prepared canal. The Agee device has a $30^{\circ}$ endoscope optic and a pistol-grip hand piece with a trigger mechanism that activates a retractable blade immediately distal to the window. A clear view of the cubital retinaculum and fasciae should be seen through the scope, with the ulnar nerve and its branches being protected by the device. The trigger mechanism is activated, and the entire device is slowly withdrawn incising the fasciae. If any at-risk structures comes in the visual view, the trigger should be released immediately and the knife is retracted. The procedure can be done both distally and proximally in a repeated manner until the fasciae is completely incised and the ulnar nerve is decompressed.

Haemostasis must be achieved before wound closure. The ulnar nerve is then checked for stability throughout total elbow motion. If the nerve is noted to be subluxatable or dislocatable, anterior transposition is indicated. (Refer to section on hypermobility of ulnar nerve)

Postoperatively, a bulky compressive dressing is given for $2-3$ days, before changing it to a simple dressing. Patients are advised to move their elbow within the limits of their comfort. They should achieve full range of motion in 1 week. Strenuous exercise is restricted for 1 week. Patients are expected to return to sports or moderate to heavy duty work in the third or fourth week.

\section{CURRENT LITERATURE ON OUTCOMES}

Numerous studies, reviewing outcomes of endoscopic cubital tunnel decompression with references to other modes of surgical techniques, have been published in the recent 10 years. In retrospective studies by Bacle $e t a l^{33}$ and Sant-Cyr et $a l^{34}$ comparing endoscopic cubital tunnel decompression with open decompression in situ and subcutaneous and submuscular anterior transposition, no significant difference in subjective improvement, Bishop score, ${ }^{35}$ (table 2) complication or recurrence was found. Moreover, there was a trend of faster recovery for decompression in situ, irrespective of either open or endoscopic technique was employed as compared with anterior transposition. ${ }^{34}$

A prospective study by Bolster et al ${ }^{19}$ comparing techniques of endoscopic cubital tunnel decompression and open decompression in situ, showed that the incision of endoscopic decompression was similar to open technique (ie, $3 \mathrm{~mm} ; 2.4 \mathrm{~cm}$ vs $2.7 \mathrm{~cm}$, respectively). However, a cadaveric study comparing open and endoscopic techniques ${ }^{18}$ revealed that a $4 \mathrm{~cm}$ open incision was equivalent to a $2 \mathrm{~cm}$ endoscopic incision, in allowing the visualisation of approximately $9 \mathrm{~cm}$ proximal and $9 \mathrm{~cm}$ distal to the medial epicondyle. The tourniquet time for open decompression in situ was significantly shorter by an average of 7 min when compared with the endoscopic technique. ${ }^{19}$ While both techniques were able to achieve early relief of symptoms and patient's satisfaction, no difference in pain, Disabilities of the Arm, Shoulder and Hand (DASH) score ${ }^{36}$ and Bishop score (table 2) were found between the two techniques. Watts and Bain $^{32}$ also showed that there was no functional difference between open and endoscopic decompression. Nevertheless, a better patients' satisfaction was associated with endoscopic cubital tunnel decompression. A retrospective study by Dützmann et $\mathrm{ll}^{37}$ showed that $76 \%$ of patients who underwent endoscopic cubital tunnel decompression were able to return to work within 7 days as opposed to that of only $18 \%$ of patients who underwent open decompression in situ.

Recently, two randomised controlled studies ${ }^{38} 39$ and four systematic reviews/meta-analysis ${ }^{40-43}$ comparing endoscopic and open cubital tunnel decompression found no difference in pain score reduction, Bishop score, DASH score and patients' satisfaction among the two techniques. While no difference was found in the overall complication rate between the two techniques, ${ }^{4041}$ a higher incidence of haematoma was noted for the endoscopic cubital tunnel decompression. ${ }^{32} 3842$ In contrast, patients with endoscopic cubital tunnel decompression tended to experience less scar pain and elbow pain than those with open release in situ. $^{39} 4142$

Despite the endoscopic technique gaining popularity, the study of the long-term outcomes for endoscopic cubital tunnel decompression remained limited. In a 82-month average follow-up, Spies $e a^{44}$ demonstrated that the improvement of functional outcomes postendoscopic cubital tunnel decompression was maintained in 51 patients.

\section{ENDOSCOPIC ULNAR NERVE DECOMPRESSION AND ANTERIOR TRANSPOSITION}

In patients with cubital tunnel syndrome with their ulnar nerves are indicated to be anteriorly transposed, for example, the presence of scarring and ulnar nerve hypermobility, the procedure can still be performed under endoscopic guidance by the creation of an additional volar portal. ${ }^{845} 46$

\section{HYPERMOBILITY OF ULNAR NERVE}

Hypermobility of the ulnar nerve remains to be a factor of consideration during ulnar nerve decompression in cubital tunnel syndrome. In a randomised controlled study by Bartels et al, ${ }^{12}$ which revealed hypermobile nerves treated with decompression alone had comparable outcomes as anterior transposition, many would recommend concomitant ulnar nerve transposition at the time of surgical decompression. ${ }^{481647-49}$

\section{How to determine if someone has subluxatable nerve}

Calfee et al noted $37 \%$ of adults have hypermobility of the ulnar nerve. ${ }^{50}$ Nerve hypermobility has not been found to be associated with symptomatic cubital tunnel syndrome. ${ }^{50}$ Cases in which ulnar nerves are decompressed in situ, a subluxatable or dislocatable nerve may result in recurrent symptoms. In these cases, anterior transposition is recommended. Among 
our authors, TC only performs anterior transposition for instability if the instability is clinically symptomatic, ${ }^{51}$ while GIB and MWMF perform anterior transposition if gross instability is found either preoperatively or intraoperatively. ${ }^{8}$

Ulnar nerve stability can be assessed by placing a finger proximal and posterior to the medial epicondyle with the elbow in full flexion. ${ }^{50}$ When a patient is actively extending the arm, if his ulnar nerve can be palpated either anterior to or beneath the examiner's finger, the nerve is described as dislocatable or perched, respectively. If the nerve cannot be felt, the nerve is defined as stable. Recently, preoperative ultrasound has been proposed to assess the stability of the nerve. It is noted that ultrasound findings have a better correlation with intra-operative findings in nerve hypermobility. ${ }^{52}$

\section{Indication for anterior transposition}

- Hostile bed of the ulnar nerve, for example, excessive scarring from previous trauma and excessive osteophytes in elbow osteoarthritis.

- Cubitus valgus.

- Ulnar nerve hypermobility. ${ }^{47}$

- Recurrent cubital tunnel syndrome (in selected cases only - which incomplete release or a new conpressive site is suspected)

\section{Contraindications}

- Previous trauma or surgery to the ulnar nerve and/or elbow.

- Severe elbow contracture.

- Concomitant pathology requiring open surgery such as corrective osteotomy for distal humeral malalignment.

- Patients' particular condition necessitating submuscular transposition, for example, patients who are slim and are susceptible to ulnar nerve irritation.

- Limited external rotation of the shoulder:

- relative contraindication-lack of surgeons' expertise.

\section{SURGICAL PROCEDURE FOR ENDOSCOPIC ULNAR NERVE DECOMPRESSION AND ANTERIOR TRANSPOSITION}

Endoscopic ulnar nerve release is first performed as described in the 'Endoscopic cubital tunnel decompression' section, using either task-specific instruments, for example, Storz instruments (Karl Storz) or specific designed cannula (Integra LifeSciences). In addition, we must excise the previously identified MIMS during decompression (figures 6 and 7). It is noted that MIMS can potentially become a new site of impingement along the new course of the ulnar nerve.

In order to mobilise the ulnar nerve circumferentially prior to the transposition, an additional subcutaneous volar portal is created just distal to the medial epicondyle. A nylon tape is then introduced into this portal for the manipulation of the nerve (figure 7). The ulnar nerve, together with its accompanied vessels are dissected from the surrounding soft tissue under endoscopic guidance. The now freed ulnar nerve is transposed to a subcutaneous space, anterior to the medial condyle, developed by tunnel forceps or spatula.

Once the ulnar nerve is in position, the entire 'new' course is inspected to ensure that the nerve runs smoothly with no kinking or new site of compression. In order to prevent the nerve from falling back behind the epicondyle, the medial condyle is rasped to promote adhesion to the adjacent soft tissue. In addition, subcutaneous tissue is sutured to the medial condyle. A fascial sling from the flexor pronator muscle complex can also be raised to secure the nerve in its new position. Prior to closure, the nerve is checked for its stability throughout total elbow motion. The tourniquet is then deflated and haemostasis is achieved. The wound is closed in layers.

Postoperatively, the elbow is kept in flexed position for 10 days by using an arm sling. Gentle active elbow mobilisation is allowed out of the sling. Patients are advised not to straighten their elbow till day 11. When they can resume light duties after 10 days, they should refrain from performing moderate to heavy duties or return to sports for 6-12 weeks.

\section{CURRENT LITERATURE ON OUTCOMES}

For endoscopic technique of cubital tunnel decompression and anterior transposition, Jiang et $a l^{53}$ first described the use of carbon dioxide insufflation to create a potential space for ulnar nerve dissection and transposition in 2012. However, it was the creation of an additional volar portal in assisting the mobilisation of ulnar nerve described in two different studies in 2014 that gained acceptance. ${ }^{45} 46$ Similar techniques of using an additional portal were subsequently published. ${ }^{5455}$ Until now, only results of cases series are available. The short-term outcomes (ie, up to 24 months follow-up) of endoscopic cubital tunnel decompression and anterior transposition were promising, with $75 \%$ achieving either good or excellent Bishop score. ${ }^{45}$ Improvement in McGowen grades and grip strength were also noted in the study by Wong et al. No complication was noted in both studies by Wong et al and Morse et al. ${ }^{4655}$ However, Martin et al described 4 out of 52 patients suffered from a worsening of symptoms post-transposition. ${ }^{45}$ A case of haematoma was also noted.

\section{FUTURE PERSPECTIVES}

Results of endoscopic-assisted techniques for the surgical management of cubital tunnel syndrome appear promising. Yet, for any proposed technique, it needs to achieve at least comparable subjective and objective outcomes, complication rate and recurrence rate and to withstand over time. Currently, there is a lack of adequately powered, prospective, preferably doubleblinded, randomised study to compare endoscopic cubital tunnel decompression with open decompression in situ. In addition, long-term outcome for endoscopic cubital tunnel decompression remains deficient. A cost analysis is also recommended to justify the additional cost for the use of endoscopic instruments.

For endoscopic cubital tunnel decompression and anterior transposition, only a few case series are currently available. Further studies are needed to compare the outcomes of endoscopic and open ulnar nerve anterior transposition in both short term and long term.

Contributors All authors have the following: substantial contributions to the conception or design of the work, or the acquisition, analysis or interpretation of data. Drafting the work or revising it critically for important intellectual content. Final approval of the version published. Agreement to be accountable for all aspects of the work in ensuring that questions related to the accuracy or integrity of any part of the work are appropriately investigated and resolved.

Funding The authors have not declared a specific grant for this research from any funding agency in the public, commercial or not-for-profit sectors.

Competing interests None declared.

Patient consent for publication Not required.

Provenance and peer review Not commissioned; externally peer reviewed.

ORCID iD

Gregory lan Bain http://orcid.org/0000-0002-3258-996X

\section{REFERENCES}

1 Dellon AL, Lee Dellon A. Review of treatment results for ulnar nerve entrapment at the elbow. J Hand Surg Am 1989;14:688-700. 
2 McGOWAN AJ. The results of transposition of the ulnar nerve for traumatic ulnar neuritis. J Bone Joint Surg Br 1950;32-B:293-301.

3 Goldberg BJ, Light TR, Blair SJ. Ulnar neuropathy at the elbow: results of medial epicondylectomy. J Hand Surg Am 1989;14:182-8.

4 Staples JR, Calfee R. Cubital tunnel syndrome: current concepts. J Am Acad Orthop Surg 2017;25:e215-24.

5 Law TY, Hubbard ZS, Chieng LO, et al. Trends in open and endoscopic cubital tunnel release in the Medicare patient population. Hand 2017;12:408-12.

6 Fok MWM, Bain G. Ulnar Nerve Pathology and Treatment Rationale. In: Bain G, Eygendaal D, van Riet R, eds. Surgical techniques for trauma and sports related injuries of the elbow. Berlin, Heidelberg: Springer, 2020: 727-9. doi:10.1007/978-3662-58931-1 98

7 Polatsch DB, Melone CP, Beldner S, et al. Ulnar nerve anatomy. Hand Clin 2007;23:283-9.

8 Bain G, Fok MWM. Endoscopic Ulnar Nerve Decompression and Transposition. In: Bain G, Eygendaal D, van Riet R, eds. Surgical techniques for trauma and sports related injuries of the elbow. Berlin, Heidelberg: Springer, 2020: 739-44. doi:10.1007/978-3662-58931-1_100

9 Learmonth JR. A technique for transplanting the ulnar nerve. Surg Gynecol Obstet $1942 ; 75: 792-3$

10 Keiner D, Gaab MR, Schroeder HWS, et al. Comparison of the long-term results of anterior transposition of the ulnar nerve or simple decompression in the treatment of cubital tunnel syndrome--a prospective study. Acta Neurochir 2009;151:311-6.

11 Biggs M, Curtis JA. Randomized, prospective study comparing ulnar neurolysis in situ with submuscular transposition. Neurosurgery 2006;58:296-304.

12 Bartels RHMA, Verhagen WIM, van der Wilt GJ, et al. Prospective randomized controlled study comparing simple decompression versus anterior subcutaneous transposition for idiopathic neuropathy of the ulnar nerve at the elbow: Part 1. Neurosurgery 2005;56:522-30.

13 Gervasio 0, Gambardella G, Zaccone C, et al. Simple decompression versus anterior submuscular transposition of the ulnar nerve in severe cubital tunnel syndrome: a prospective randomized study. Neurosurgery 2005;56:108-17.

14 Caliandro P, La Torre G, Padua R, et al. Treatment for ulnar neuropathy at the elbow. Cochrane Database Syst Rev 2016;11:CD006839.

15 Soltani AM, Best MJ, Francis CS, et al. Trends in the surgical treatment of cubital tunnel syndrome: an analysis of the National survey of ambulatory surgery database. J Hand Surg Am 2013;38:1551-6.

16 O'Grady E, Power D, Tan S. Current attitudes regarding surgical treatment of cubital tunnel syndrome in the UK. J Hand Surg Eur Vol 2017;42:959-60.

17 Tsai TM, Bonczar M, Tsuruta T, et al. A new operative technique: cubital tunnel decompression with endoscopic assistance. Hand Clin 1995:11:71-80.

18 Said J, Frizzell K, Heimur J, et al. Visualization during endoscopic versus open cubital tunnel decompression: a cadaveric study. J Hand Surg Am 2019;44:697.e1-697.e6.

19 Bolster MAJ, Zöphel OT, van den Heuvel ER, et al. Cubital tunnel syndrome: a comparison of an endoscopic technique with a minimal invasive open technique. J Hand Surg Eur Vol 2014;39:621-5.

20 Stadie AT, Keiner D, Fischer G, et al. Simple endoscopic decompression of cubital tunnel syndrome with the Agee system. Oper Neurosurg 2010;66:ons325-32.

21 Hoffmann R, Siemionow M. The endoscopic management of cubital tunnel syndrome. $J$ Hand Surg Am 2006;31:23-9.

22 Flores LP. Endoscopically assisted release of the ulnar nerve for cubital tunnel syndrome. Acta Neurochir 2010;152:619-25.

23 Yoshida A, Okutsu I, Hamanaka I. Endoscopic anatomical nerve observation and minimally invasive management of cubital tunnel syndrome. J Hand Surg Eur Vol 2009:34:115-20.

24 Ahčan U, Zorman P. Endoscopic decompression of the ulnar nerve at the elbow. J Hand Surg Am 2007;32:1171-6.

25 Mirza A, Reinhart MK, Bove J, et al. Scope-assisted release of the cubital tunnel. J Hand Surg Am 2011:36:147-51

26 Hoffmann R, Lubahn J. Endoscopic cubital tunnel release using the Hoffmann technique. J Hand Surg Am 2013;38:1234-9.

27 Bain Gl, Bajhau A. Endoscopic release of the ulnar nerve at the elbow using the Agee device: a cadaveric study. Arthroscopy 2005;21:691-5.

28 Cobb TK, Sterbank PT, Lemke JH. Endoscopic cubital tunnel recurrence rates. Hand 2010;5:179-83.

29 Cobb T. PROCEDURE 53 - Endoscopic Cubital Tunnel Release. In: Lee DH, Neviaser RJ, eds. Operative techniques: shoulder and elbow surgery. W.B. Saunders, 2010: 891-903. doi:10.1016/B978-1-4160-3278-6.50064-5
30 Hoffmann R, Siemionow M. Miniinvasive, endoscopic cubital tunnel release. J Hand Surg Am 2003;28 (Supp 1):72. doi:10.1016/50363-5023(03)80438-0

31 Cobb TK. Endoscopic cubital tunnel release. J Hand Surg Am 2010;35:1690-7.

32 Watts AC, Bain Gl. Patient-rated outcome of ulnar nerve decompression: a comparison of endoscopic and open in situ decompression. J Hand Surg Am 2009;34:1492-8.

33 Bacle G, Marteau E, Freslon M, et al. Cubital tunnel syndrome: comparative results of a multicenter study of 4 surgical techniques with a mean follow-up of 92 months. Orthop Traumatol Surg Res 2014;100:S205-8.

34 Saint-Cyr M, Lakhiani C, Tsai T-M. Surgical management of cubital tunnel syndrome: a comparative analysis of outcome using four different techniques. Eur J Plast Surg 2013;36:693-700.

35 Kleinman WB, Bishop AT. Anterior intramuscular transposition of the ulnar nerve. J Hand Surg Am 1989;14:972-9.

36 Hudak PL, Amadio PC, Bombardier C. Development of an upper extremity outcome measure: the DASH (disabilities of the arm, shoulder and hand) [corrected]. The Upper Extremity Collaborative Group (UECG). Am I Ind Med 1996;29:602-8.

37 Dützmann S, Martin KD, Sobottka S, et al. Open vs retractor-endoscopic in situ decompression of the ulnar nerve in cubital tunnel syndrome: a retrospective cohort study. Neurosurgery 2013;72:605-16.

38 Schmidt S, Kleist Welch-Guerra W, Matthes M, et al. Endoscopic vs open decompression of the ulnar nerve in cubital tunnel syndrome: a prospective randomized double-blind study. Neurosurgery 2015;77:960-70.

39 Krejčí T, Večeřa Z, Krejčí O, et al. Comparing endoscopic and open decompression of the ulnar nerve in cubital tunnel syndrome: a prospective randomized study. Acta Neurochir 2018;160:2011-7.

40 Ren Y-M, Zhou X-H, Qiao H-Y, et al. Open versus endoscopic in situ decompression in cubital tunnel syndrome: a systematic review and meta-analysis. Int I Surg 2016;35:104-10.

41 Byvaltsev VA, Stepanov IA, Kerimbayev TT. A systematic review and meta-analysis comparing open versus endoscopic in situ decompression for the treatment of cubital tunnel syndrome. Acta Neurol Belg 2020;120:90-8.

42 Buchanan PJ, Chieng LO, Hubbard ZS, et al. Endoscopic versus open in situ cubital tunnel release: a systematic review of the literature and meta-analysis of 655 patients. Plast Reconstr Surg 2018;141:679-84.

43 Toirac A, Giugale JM, Fowler JR. Open versus endoscopic cubital tunnel in situ decompression: a systematic review of outcomes and complications. Hand 2017; 12:229-35

44 Spies CK, Schäfer M, Langer MF, et al. Functional outcome after endoscopic assisted release of the ulnar nerve for cubital tunnel syndrome: mid-to-long term results. Int Orthop 2018;42:1331-7.

45 Martin K-D, Dützmann S, Sobottka SB, et al. Retractor-endoscopic nerve decompression in carpal and cubital tunnel syndromes: outcomes in a small series. World Neurosurg 2014;82:e361-70.

46 Morse LP, McGuire DT, Bain GI. Endoscopic ulnar nerve release and transposition. Tech Hand Up Extrem Surg 2014;18:10-14.

47 Matzon JL, Lutsky KF, Hoffler CE, et al. Risk factors for ulnar nerve instability resulting in transposition in patients with cubital tunnel syndrome. J Hand Surg Am 2016:41:180-3.

48 DeGeorge B, Kakar S. Decision-making factors for ulnar nerve transposition in cubital tunnel surgery. J Wrist Surg 2019;08:168-74.

49 Yahya A, Malarkey AR, Eschbaugh RL, et al. Trends in the surgical treatment for cubital tunnel syndrome: a survey of members of the American Society for surgery of the hand. Hand 2018;13:516-21.

50 Calfee RP, Manske PR, Gelberman RH, et al. Clinical assessment of the ulnar nerve at the elbow: reliability of instability testing and the association of hypermobility with clinical symptoms. J Bone Joint Surg Am 2010;92:2801-8.

51 Cobb TK, Walden AL, Merrell PT, et al. Setting expectations following endoscopic cubital tunnel release. Hand 2014;9:356-63.

52 Rutter M, Grandizio LC, Malone WJ, et al. The use of preoperative dynamic ultrasound to predict ulnar nerve stability following in situ decompression for cubital tunnel syndrome. J Hand Surg Am 2019;44:35-8.

53 Jiang S, Xu W, Shen Y, et al. Endoscopy-assisted cubital tunnel release under carbon dioxide insufflation and anterior transposition. Ann Plast Surg 2012;68:62-6.

$54 \mathrm{LuiTH}$. Endoscopic anterior subcutaneous transposition of the ulnar nerve. Arthrosc Tech 2017;6:e1451-6.

55 Wong JKF, Hsu CC, Lin CH, et al. Endoscopy-assisted subfascial anterior transposition of the ulnar nerve for the treatment of cubital tunnel syndrome. J Plast Reconstr Aesthet Surg 2016:69:1704-10. 